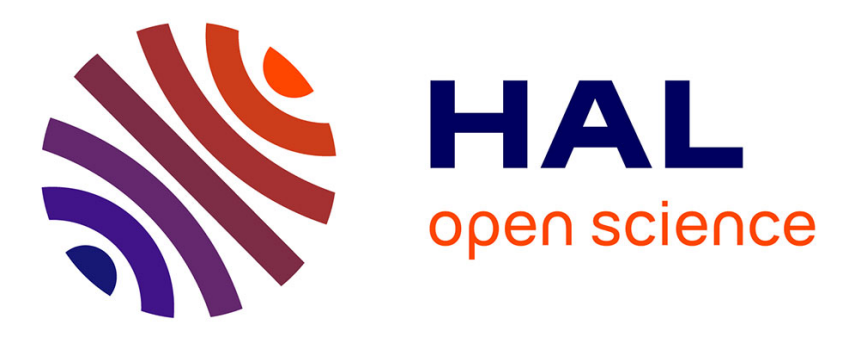

\title{
Design and Experimental Validation of a Supersonic Concentric Micro Gas Turbine
}

\author{
Gabriel Vézina, Hugo Fortier-Topping, François Bolduc-Teasdale, David \\ Rancourt, Mathieu Picard, Jean-Sébastien Plante, Martin Brouillette, Luc \\ Frechette
}

\section{To cite this version:}

Gabriel Vézina, Hugo Fortier-Topping, François Bolduc-Teasdale, David Rancourt, Mathieu Picard, et al.. Design and Experimental Validation of a Supersonic Concentric Micro Gas Turbine. Journal of Turbomachinery, 2016, 138 (2), pp.021007. 10.1115/1.4031863 . hal-01918148

\author{
HAL Id: hal-01918148 \\ https://hal.science/hal-01918148
}

Submitted on 23 Nov 2018

HAL is a multi-disciplinary open access archive for the deposit and dissemination of scientific research documents, whether they are published or not. The documents may come from teaching and research institutions in France or abroad, or from public or private research centers.
L'archive ouverte pluridisciplinaire HAL, est destinée au dépôt et à la diffusion de documents scientifiques de niveau recherche, publiés ou non, émanant des établissements d'enseignement et de recherche français ou étrangers, des laboratoires publics ou privés. 


\title{
Design and Experimental Validation of a Supersonic Concentric Micro Gas Turbine
}

\author{
Gabriel Vézina $^{\mathrm{a}, 1}$, Hugo Fortier-Topping ${ }^{\mathrm{a}}$, François Bolduc-Teasdale ${ }^{\mathrm{a}}$, David Rancourt ${ }^{\mathrm{b}}$, \\ Mathieu Picard ${ }^{a}$, Jean-Sébastien Plante ${ }^{a}$, Martin Brouillette ${ }^{c}$, Luc Fréchette $^{d}$
}

${ }^{a}$ CAMUS Laboratory, Université de Sherbrooke, 2500 Boulevard University, Sherbrooke, QC J1K 2R1, Canada

bAerospace Systems Design Laboratory, Georgia Institute of Technology, 275 Ferst Dr., Atlanta, GA 30332

'LOCUS Laboratory, Université de Sherbrooke, 2500 Boulevard University, Sherbrooke, QC J1K 2R1, Canada

dMICROS Laboratory, Université de Sherbrooke, 2500 Boulevard University, Sherbrooke, QC J1K 2R1, Canada

This paper presents the design and experimental results of a new micro gas turbine archi-tecture exploiting counterflow within a single supersonic rotor. This new architecture, called the supersonic rim-rotor gas turbine (SRGT), uses a single rotating assembly incorporating a central hub, a supersonic turbine rotor, a supersonic compressor rotor, and a rim-rotor. This SRGT architecture can potentially increase engine power density while significantly reducing manufacturing costs. The paper presents the preliminary design of a $5 \mathrm{~kW}$ SRGT prototype having an external diameter of $72.5 \mathrm{~mm}$ and rotational speed of 125,000 rpm. The proposed aerodynamic design comprises a single stage super-sonic axial compressor, with a normal shock in the stator, and a supersonic impulse tur-bine. A pressure ratio of 2.75 with a mass flow rate of $130 \mathrm{~g} / \mathrm{s}$ is predicted using a $1 D$ aerodynamic model in steady state. The proposed combustion chamber uses an annular reverse-flow configuration, using hydrogen as fuel. The analytical design of the combus-tion chamber is based on a OD model with three zones (primary, secondary, and dilution), and computational fluid dynamics (CFD) simulations are used to validate the analytical model. The proposed structural design incorporates a unidirectional carbon-fiber-reinforced polymer rim-rotor, and titanium alloy is used for the other rotating compo-nents. An analytical structural model and numerical validation predict structural integ-rity of the engine at steady-state operation up to $1000 \mathrm{~K}$ for the turbine blades. Experimentation has resulted in the overall engine performance evaluation. Experimen-tation also demonstrated a stable hydrogen flame in the combustion chamber and struc-tural integrity of the engine for at least $30 \mathrm{~s}$ of steady-state operation at 1000K.

\footnotetext{
${ }^{1}$ Corresponding author.
}

\section{Introduction}

Low cost and high power density are key characteristics for portable and transportation power units such as aircraft auxiliary power units, emergency generators, and range extenders for electric cars. Today's gas turbines are expensive and piston engines do not offer enough power density for high power applications [1]. The SRGT can lead to high power density while maintaining 
low manufacturing costs by using a single supersonic rotating assembly. The SRGT uses a single concentric rotating disk (as shown in Fig. 1). The compressor and turbine rotors are located inside a carbon fiber rim-rotor that keeps the components in compression, to handle high centrifugal loads caused at high rotational speed.

A supersonic impulse compressor comprised of a rotor (located between the turbine rotor and the rim-rotor) and a stator increases the air pressure in a very short distance. Subsonic combustion takes place in an annular reverse-flow combustion chamber, with the inlet and the exhaust on the same side of the rotating disk; combustion products are expanded in the turbine stator. The highspeed flow is then converted into torque by the impulse turbine located beneath the compressor rotor. Finally, the mechanical power can eventually be converted to electricity by a high-speed generator.

Small high-speed turbomachinery using the rim-rotor architecture present the potential for high power density, which makes it interesting for many mobile applications $[2,3]$. The key concept of these engine configurations is that the rim-rotor supports high centrifugal loads and keeps rotating components in compression, allowing the use of ceramic turbine blades. The mechanical properties of ceramics allow the maximum turbine inlet temperature and rotational speed to increase, resulting in efficiency and power density gains. The rim-rotor is a key component, which provides the necessary strength to reach supersonic speed (Mach 2 and higher) $[4,5]$.

Small concentric counterflow turbomachinery has been studied in-house, based on these configurations, but no known demonstration had been performed on such a configuration. The concentric counterflow arrangement has fewer components than traditional turbomachinery, which results in low manufacturing cost of a single rotor [6-8] comprised of only a few distinct components. The addition of a rim-rotor to the counterflow configuration has the advantage of enabling supersonic compression while integrating ceramic turbine blades in a single assembly. Moreover, the location of the compressor between the turbine and the rim-rotor protects the latter from the high temperature of the exhaust gases [9]. No experimental research has demonstrated the potential of small engine supersonic turbomachinery with single rotor counterflow embedded in rim-rotor.

This paper presents the design process and experimental validation of a small scale SRGT prototype. The design process of the aerodynamic layout, the combustion chamber, and the structure of a $5 \mathrm{~kW}$ prototype are detailed. Analytical and/or numerical models are used in all three aspects of SRGT design (aerodynamics, combustion, and structural design). Finally, a test bench is designed to characterize the SRGT prototype. Experimental results from a $5 \mathrm{~kW}$ prototype are presented.

Results from a steady-state test show that the proposed concept can sustain the mechanical stresses caused by high rotational

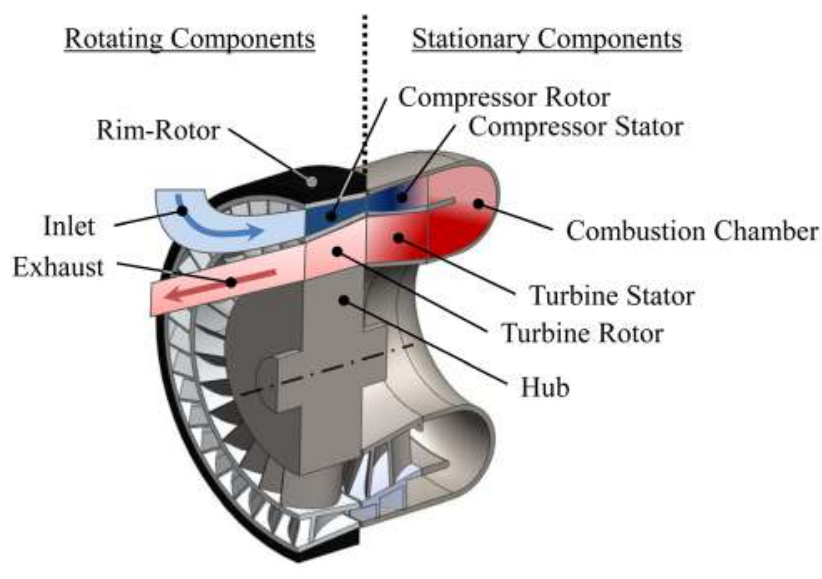

Fig. 1 SRGT speed with a turbine inlet temperature of $1000 \mathrm{~K}$. Ignition and stable combustion are demonstrated with hydrogen as a fuel. A combustion efficiency of more than $85 \%$ was reached. An acceleration from 102,000 to $117,000 \mathrm{rpm}$ was demonstrated. Although it is not possible to prove the production of indicated power during the acceleration, a power gain of $1500 \mathrm{~W}$ was measured.

\section{Prototype Requirements}

The main research objective is to study the feasibility of SRGT turbine by attempting to demonstrate positive indicated power in steady-state operation. This objective leads to specific objectives for the aerodynamic and combustor designs. For the aerodynamic design, the compressor must provide an air mass flow at a pressure ratio of 2.75 to produce positive indicated power. To achieve the desired pressure ratio, the compressor must reach a supersonic velocity of Mach 1.4 at the compressor inlet.

For the structure, a rotational speed of $125,000 \mathrm{rpm}$ is selected to achieve supersonic compression. A turbine inlet temperature of $1000 \mathrm{~K}$ in steady-state operation is set to allow the use of easy-tomanufacture materials. The outside diameter of the prototype is essentially fixed by limits imposed by the existing test bench and the use of readily available materials.

For the combustor, the aim is to demonstrate that a hydrogen flame can be ignited and stabilized in the combustion chamber. Hydrogen is selected for its high laminar flame velocity and its wide ignition range. A $30 \mathrm{~s}$ total operation time is targeted to reach dynamic and thermal quasi-steady state of the rotor. Technical requirements that satisfy those objectives are listed in Table 1.

\section{Proposed Design}

The layout of SRGT system shown in Fig. 2 presents the major components of inlet, compressor and turbine rotors and stators, combustion chamber, and exhaust. The compressor stator is used to convert dynamic pressure of the flow coming out of the compressor rotor into static pressure. Because the flow coming out of the rotor is supersonic, the stator uses oblique and normal shocks to convert the dynamic pressure into static pressure. The turbine stator converts the static pressure into dynamic pressure using a converging-diverging nozzle. The combustion chamber has an annular reverse-flow configuration, with the inlet and the outlet on the same side.

The SRGT rotor is an assembly comprising the turbine rotor, the compressor rotor, a thin aluminum ring, and the rim-rotor. Both rotors and the aluminum ring are shrink fit inside the rim-rotor. The turbine and compressor rotors are made of grade 5 titanium alloy to allow easy machining while providing good structural strength at high temperature. The turbine hub is hollow to fit the prototype on the starter shaft. Mass is added around the center of the hub during dynamic balancing of the rotor assembly. The rim-rotor is made of a high modulus carbon fiber impregnated with polyetheretherketone, a high-temperature thermoplastic. The rim-rotor preloads the inner components in compression, limiting the stress levels caused by the high centrifugal field at high rotational speeds $(>100,000 \mathrm{rpm})$. The thin aluminum ring is fitted between the compressor blades and the rim-rotor to distribute the

Table 1 Prototype requirements

\begin{tabular}{lc}
\hline Parameter & Value \\
\hline Power & $5 \mathrm{~kW}$ \\
Relative inlet Mach number & 1.4 \\
Pressure ratio & 2.75 \\
Mass air flow & $130 \mathrm{~g} / \mathrm{s}$ \\
Combustion time & $30 \mathrm{~s}$ \\
Fuel & Hydrogen \\
Turbine inlet temperature & $1000 \mathrm{~K}$ \\
Outside diameter & $72.5 \mathrm{~mm}$ \\
\hline
\end{tabular}




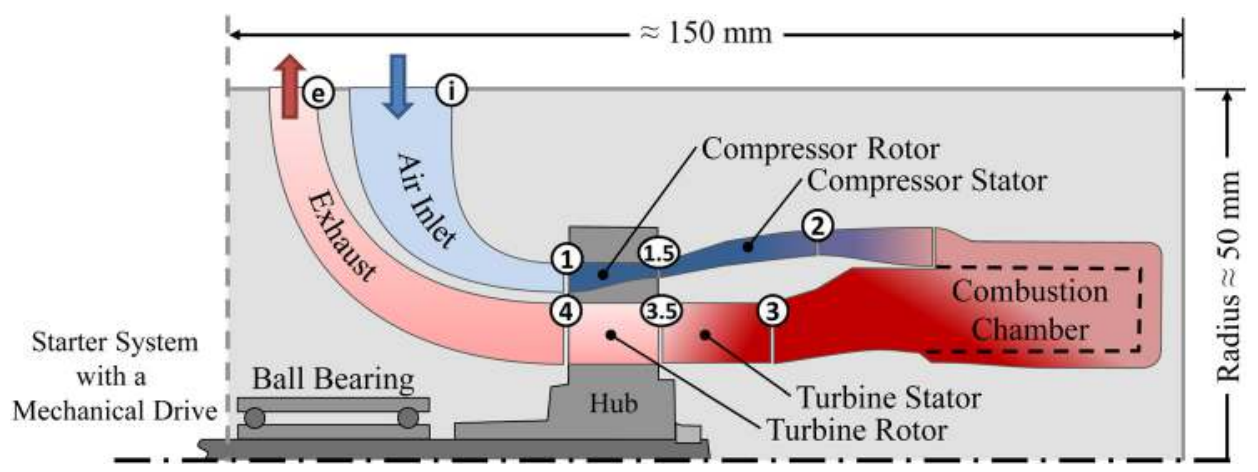

Fig. 2 SRGT layout

load of the blades on the rim-rotor. Figure 3 shows a sectional view of the engine with main dimensions.

\section{General Design Process}

The iterative design process used to develop the SRGT prototype is based on typical gas turbine design procedures as shown in Fig. 4 [10]. From prototype specifications, a preliminary study allows a thermodynamic cycle and the overall engine layout to be selected. The engine performance map allows the selection of an operating design point, from which aerodynamic and thermodynamic models have been developed to design the engine components geometry (intake, compressor, combustion chamber, turbine, and exhaust). The mechanical design validated the structural engine integrity, and a test bench has been designed to meet all the requirements for engine characterization. Finally, the first set of experimental data presented in this paper validates the SRGT gas turbine prototype performance and closes a first design iteration loop.

\section{Aerodynamic Design}

5.1 Analytical Design. The analytical aerodynamic design model includes component geometry, friction losses, heat transfer, and windage losses. The compressor stage combines an air flow inlet, a full supersonic impulse rotor, a supersonic stator with an internal normal shock, and a diffuser. The turbine stage combines a converging/diverging supersonic nozzle, a transonic impulse rotor, and a diffuser.

The aerodynamic performance evaluation of the entire engine is based on the performance evaluation of each component by discretizing the flow path at each station. Each component is simplified and modeled by an area change duct with a quasi-1D assumption in steady state. Components with blading are modeled by a cascade of identical area change duct with the same geometry

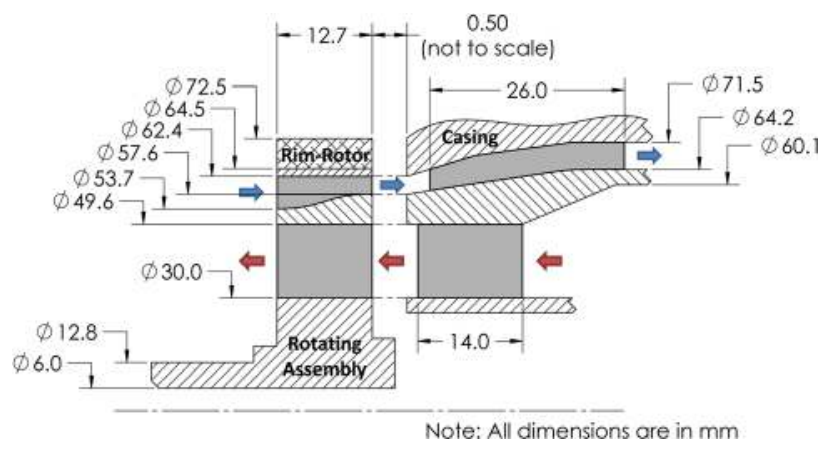

Fig. 3 Section view of SRGT with main dimensions and mass flow. Each duct is modeled with the generalized 1D continuous flow equations [11] and is discretized in 1000 equidistant control surfaces. The rotating frame is incorporated with the frozen-rotor approach [12]. Boundary layers are considered attached to walls with negligible displacement thicknesses. The trailing edge of the blades is modeled with a 1D area change without losses from the wakes.

The generalized 1D continuous flow equations [11] are used for first-order evaluation because of simplicity, but yet take into account heat transfer, wall friction, area change, molecular weight changes, and variations of mass flow rate and/or mechanical work. The generalized 1D continuous flow model neglects complex physics such as multidimensional effects, boundary layer interaction, and unsteady effects. The 1D continuous flow model used in this work (Fig. 5) is an adaptation of the generalized model.

Each flow is modeled with constant specific heat $\left(c_{p}=\mathrm{cst}\right)$, molecular weight $(\tilde{M}=\mathrm{cst})$, and mass flow rate $(\dot{m}=\mathrm{cst})$, and without mechanical work done on the fluid in the rotating frame. The fluids (air or combustion products) are modeled as perfect gases. Control surfaces within each duct are equidistant $(\mathrm{d} x=\mathrm{cst})$ and are each defined by an area $(A)$ and a hydraulic diameter $\left(D_{\mathrm{h}}\right)$.

The following equation is used to compute the local Mach number $(M)$ variation, the pressure $(P)$, the temperature $(T)$, and the density $(\rho)$ at each section of the 1D model:

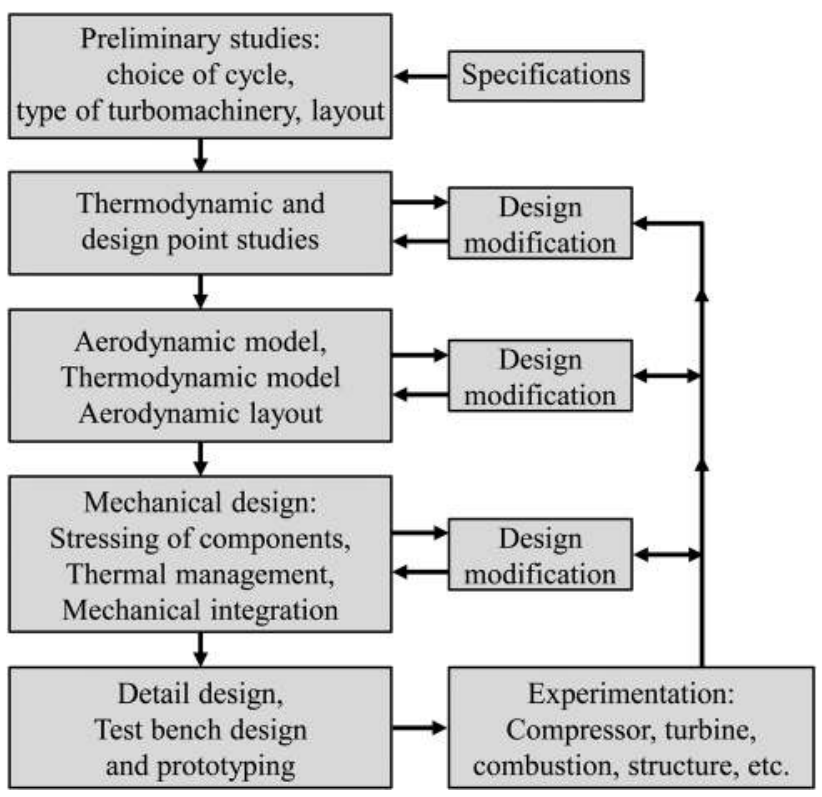

Fig. 4 SRGT gas turbine design procedure 


$$
\left[\begin{array}{c}
\left(\begin{array}{l}
\mathrm{d} M^{2} \\
M^{2}
\end{array}\right) \\
\left(\begin{array}{c}
\mathrm{d} P \\
P
\end{array}\right) \\
\left(\frac{\mathrm{d} T}{T}\right) \\
\left(\frac{\mathrm{d} \rho}{\rho}\right)
\end{array}\right]=\left[\begin{array}{ccc}
\frac{-2\left(1+\frac{\gamma-1}{2} M^{2}\right)}{1-M^{2}} & \frac{1+\gamma M^{2}}{1-M^{2}} & \frac{\gamma M^{2}\left(1+\frac{\gamma-1}{2} M^{2}\right)}{1-M^{2}} \\
\frac{\gamma M^{2}}{1-M^{2}} & \frac{-\gamma M^{2}}{1-M^{2}} & \frac{-\gamma M^{2}\left(1+(\gamma-1) M^{2}\right)}{2\left(1-M^{2}\right)} \\
\frac{(\gamma-1) M^{2}}{1-M^{2}} & \frac{1-\gamma M^{2}}{1-M^{2}} & \frac{-\gamma(\gamma-1) M^{4}}{2\left(1-M^{2}\right)} \\
\frac{M^{2}}{1-M^{2}} & \frac{-1}{1-M^{2}} & \frac{-\gamma M^{2}}{2\left(1-M^{2}\right)}
\end{array}\right]\left[\begin{array}{c}
\left(\frac{\mathrm{d} A}{A}\right) \\
\left(\frac{\mathrm{d} h+\mathrm{d} Q}{c_{p} T}\right) \\
\left(4 C_{f} \frac{\mathrm{d} x}{D_{h}}\right)
\end{array}\right]
$$

where $A$ is the cell area, $\mathrm{d} h$ is the enthalpy of reaction, $\mathrm{d} Q$ is the heat transfer, and $C_{f}$ is the Fanning friction factor. The Fanning friction factor for all aerodynamic components in the model is assumed to be between 0.005 and 0.010 , which is up to twice the typical friction factor for a supersonic flow in a constant area duct [11]. This overestimation is an approach to compensate for effects not incorporated into the model, such as the roughness, curvature lines, and multidimensional effects.

The inlet stagnation flow conditions correspond to atmospheric air. The inlet redirects a radial flow at a Mach number of 0.1 to an axial flow at a Mach number of 0.5 just before entering the compressor rotor. The compressor is an impulse type. The inlet of the compressor rotor is supersonic with an oblique shock wave on both side of each rotor blade. The rotor blade geometry is designed using the method of characteristics [11] with the objective of avoiding shock waves reflection at the design speed. The flow remains supersonic at relative constant Mach number through the entire rotor. The flow ducts between blades redirect the flow to a zero flow angle in the relative rotor frame. The compressor stator inlet is similar to the compressor rotor inlet, with an oblique shock wave on each side of each blade, without reflection. A normal shock occurs just after the oblique shock and the flow thereafter remains subsonic up to combustion chamber. The stator blades curve the flow for a maximum deflection with an axial flow at the stator outlet. The compressor diffuser is completely subsonic and reduces the flow velocity to a Mach number of 0.1 at the entrance to the combustion chamber. Figure 6 presents the model of the compressor stage.

The combustion chamber is first modeled by evaluating the thermodynamic properties of the combustion products. These are evaluated from a combustion equilibrium solver at constant pressure and enthalpy [13]. The total pressure loss in the combustion chamber is estimated from a semi-empirical model [14]. Figure 7 presents a sketch of the OD combustion chamber model.

The inlet flow at the turbine stator is assumed to be perfectly axial at a Mach number of 0.25 . The turbine stator redirects and accelerates the flow in a converging subsonic nozzle until a sonic

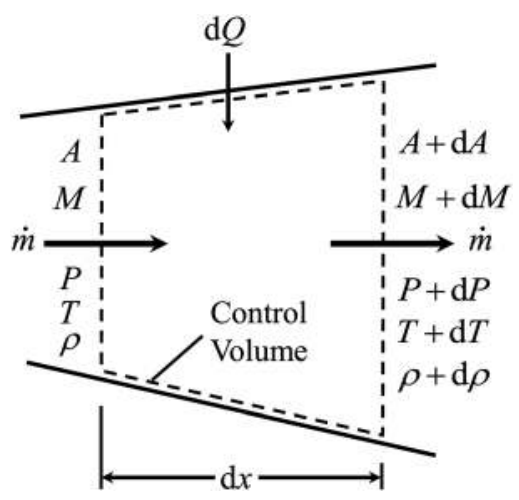

Fig. 5 Control volume of the 1D continuous flows model [11] throat. Downstream of the throat, the flow continues to accelerate in a quasi-1D divergent supersonic nozzle. The turbine stator outlet flow is uniform at a Mach number of 1.4 with a high tangential velocity component. The turbine rotor inlet flow is transonic with a relative Mach number between 0.9 and 1.1 depending of the radial position. The Mach number difference is due to the radial/tangential speed difference caused by the low hub-to-tip ratio $(\approx 0.6)$ of turbine blading. The turbine is an impulse type. Similarly to the supersonic compressor, the rotor blade geometry is designed using the method of characteristics [11] with the objective of avoiding strong shock waves in the blade passage at the design speed. The flow remains supersonic at relative constant Mach number through the entire rotor. The turbine rotor blades deflect the flow for a maximum power extraction. The turbine rotor blades are designed with aerodynamic twist to match variation in radial inlet flow angle and to minimize exhaust swirl. The exhaust is a subsonic diverging diffuser matching the static pressure with the atmospheric back pressure. Figure 8 presents the flow model of the turbine stage.

The power of the compressor rotor $\left(\dot{W}_{\text {compressor }}\right)$ and turbine rotor $\left(W_{\text {turbine }}\right)$ is directly evaluated with the total enthalpy difference $\left(\Delta h_{0}\right)$

$$
\dot{W}=\dot{m}\left(\Delta h_{0}+\delta Q\right)=\dot{m}\left(h_{0, \text { exit }}-h_{0, \text { inlet }}+\delta Q\right)
$$

5.2 Windage Losses. The windage losses caused by the high tangential speed of the rim-rotor are modeled using two different models. The losses from the peripheral surface of the rim-rotor are evaluated from those of a rotating cylinder with an empirical model from Ref. [15]

$$
\dot{W}_{\text {cylindre }}=\frac{0.455 \rho L \pi r^{4} \omega^{3}}{\left[\log _{10}\left(2 \pi r^{2} \omega / \nu\right)\right]^{2.58}}
$$

The windage losses associated with the sides of the rim-rotor are modeled using a rotating disk geometry with the empirical model from Ref. [16]

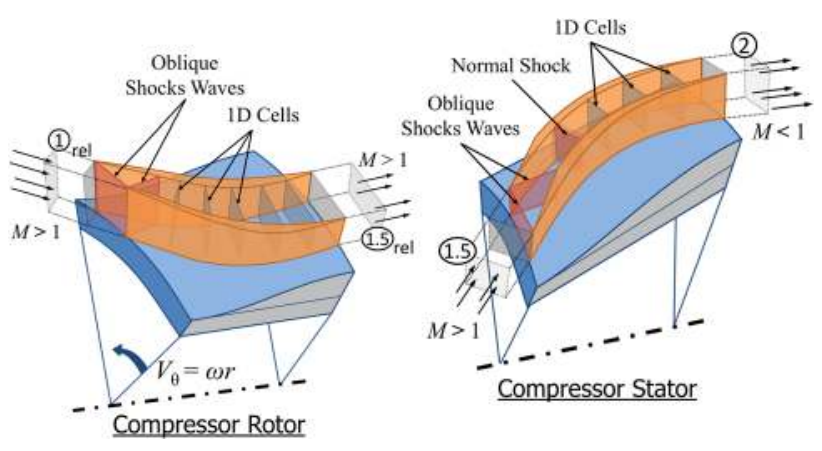

Fig. 6 Model of the compressor stage 


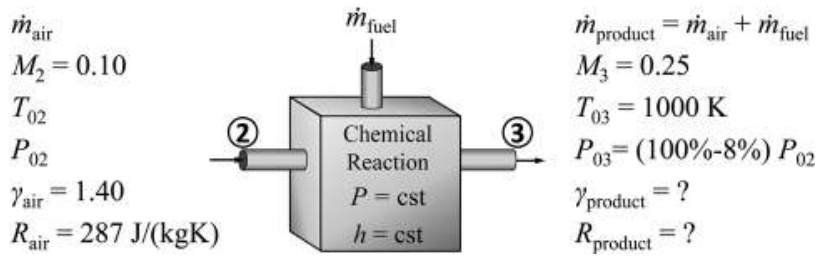

Fig. 7 Zero-dimensional combustion chamber model

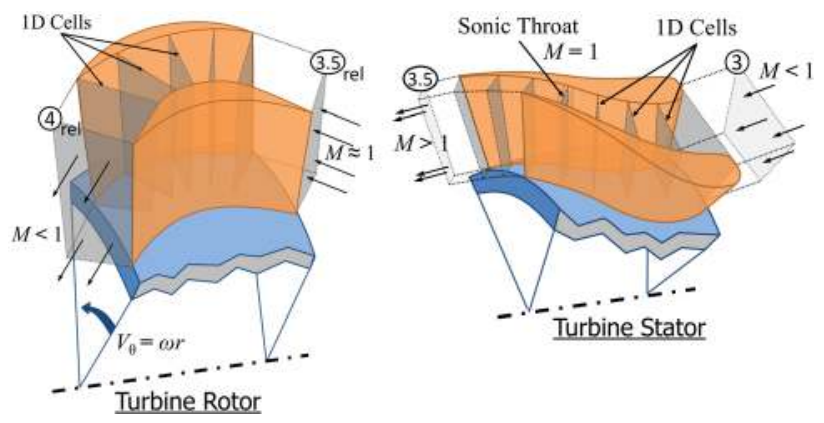

Fig. 8 Model of the turbine stage

$$
\begin{aligned}
\operatorname{Re}_{r}<10^{6} \rightarrow \dot{W}_{\text {disk }} & =\frac{1}{2} \rho r^{5} \omega^{3}\left[\frac{0.073}{\operatorname{Re}_{r}^{-0.2}}\right] \\
\operatorname{Re}_{r}>10^{6} \rightarrow \dot{W}_{\text {disk }} & =\frac{1}{2} \rho r^{5} \omega^{3}\left[\frac{0.491}{\left[\log _{10}\left(\operatorname{Re}_{r}\right)\right]^{2.58}}\right]
\end{aligned}
$$

In Eqs. (3) and (4), the gas properties are those surrounding the rim-rotor, where $L$ and $r$ are length and radius of the rimrotor and $\mathrm{Re}_{r}$ is the Reynolds number based on the radius. The power loss predicted for windage losses is multiplied by a factor of 1.35 based on correlations obtained from flywheel experimentations [5].

5.3 Prototype. Figure 9 presents the geometry of compressor and turbine prototype and their respective speed triangles evaluated at mean radius. The rotating assembly is $12.7 \mathrm{~mm}$ wide. The
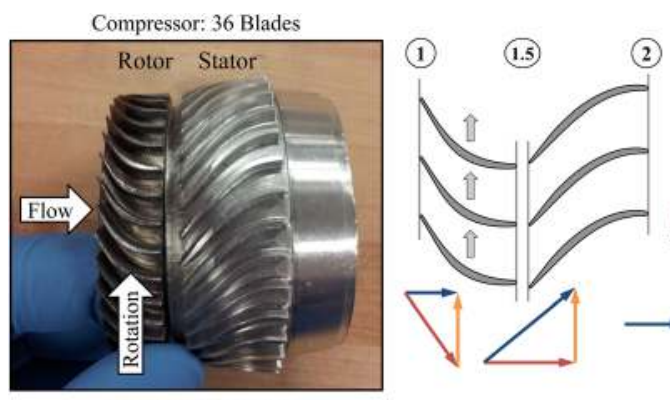

Turbine: 18 Blades
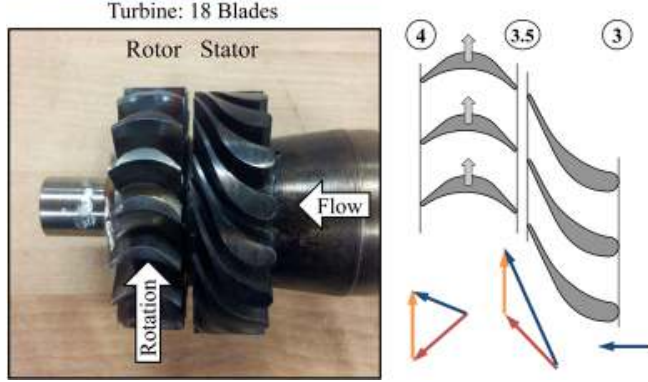

(3)

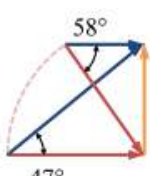

$47^{\circ}$

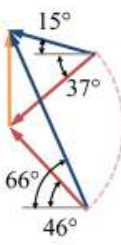

Fig. 9 Compressor and turbine geometries compressor rotor and stator have 36 blades each and the nominal radius is $30 \mathrm{~mm}$. The hub-tip ratio of the compressor is around 0.90 . The turbine rotor and stator have 18 blades each and the nominal radius is $20 \mathrm{~mm}$. The hub-to-tip ratio of the turbine is 0.60 . The anticipated performances for the aerodynamic components at the design point are total-to-total isentropic efficiencies of $70 \%$ for the compressor stage and of $87 \%$ for the turbine stage. These component efficiencies are realistic when compare to stateof-the-art of axial supersonic compressors and turbines. Experimental work on axial supersonic compressor stage has already demonstrated the capability for a single stage to produce a pressure ratio higher than 3.0 with isentropic efficiency higher than $75 \%$ [17]. Experimental work on axial supersonic turbine stage has already demonstrated the capability to expand a pressure ratio of 3.35 by turbine stage with an isentropic efficiency higher than $85 \%$ [18].

\section{Combustion Chamber Design}

The combustion chamber is first sized with empirical equations from a OD model. Then, the combustion chamber is modeled in $3 \mathrm{D}$ and full 3D CFD numerical analysis is performed. The 3D model is used to optimize the dimensions of the combustion chamber and to predict its performance at engine operating conditions.

6.1 0D Model. Before starting the design of the combustion chamber, the criteria on different performance parameters are set. These criteria are not fixed with the aim of an optimal system performance. The combustor requirements for the prototype are presented in Table 2.

The combustion chamber is designed using the Mellor design process [19], where the combustor is split in four different zones: the passages around the liner, the primary zone in the liner, the secondary zone, and the dilution zone. Since the primary zone anchors the flame, it must provide sufficient time, temperature, and turbulence to achieve mostly complete combustion of the incoming fuel-air mixture. The secondary zone then completes combustion, and the dilution zone subsequently lowers and evens the temperature of the combustion gases to a tolerable level for the turbine blades.

The technique used in the OD model is based on assumptions on flow speed in the passages around the liner and in the primary zone. The flow speed in the combustor primary zone $\left(V_{\text {primary }}\right)$ should be limited between 6 and $12 \mathrm{~m} / \mathrm{s}$ and between 25 and $60 \mathrm{~m} /$ $\mathrm{s}$ in the passages $\left(V_{P}\right)$ around the liner [1]. For the $5 \mathrm{~kW}$ prototype, the speeds are, respectively, set to 9 and $50 \mathrm{~m} / \mathrm{s}$.

The first design step using the $0 \mathrm{D}$ model is to calculate the mass air flow needed for each zone of the combustor. First, the fuel mass flow for the combustor is calculated to get the average outlet temperature needed. The mass air flow of the primary zone is then calculated to get a stoichiometric ratio just over 1 . The mass air flow of the second zone is calculated to bring down the stoichiometric ratio to 0.6 , including the air of the first zone. The remaining air is assigned to the dilution zone [14], since no blade cooling is used in this small scale turbine.

In the second step of the OD model, the main combustor dimensions are calculated using the following equations: The liner cross

Table 2 Combustor design requirements

\begin{tabular}{lc}
\hline Requirements & Level \\
\hline Pattern factor & $0.2-0.5$ \\
Total pressure losses & $4-8 \%$ \\
Average outlet temperature & $1000 \mathrm{~K}$ \\
Combustion efficiency & $>95 \%$ \\
Outlet Mach number & 0.25 \\
Fuel & Hydrogen \\
\hline
\end{tabular}


section area $\left(A_{L}\right)$ is computed using mass conservation (Eq. (5)), using the thermodynamic properties of the first zone. The height of the liner $\left(H_{L}\right)$ is then calculated with the pitch diameter $\left(D_{L}\right)$ (Eq. (6)). The pitch diameter of the combustor is the average of the pitch diameters of the compressor outlet and the inlet of the turbine. Finally, the combustor length $\left(L_{L}\right)$ is computed based on the target pattern factor (PF) at the outlet and from the anticipated total pressure losses caused by the passage of air through liner holes $\left(\Delta P_{L} / q_{\text {ref }}\right)$ (Eq. (7)). The pressure loss caused by the liner typically represents about $60 \%$ of the total pressure losses in the combustion chamber. The pattern factor is fixed to a maximum value of 0.25

$$
\begin{gathered}
A_{L}=\frac{\dot{m}_{C 1}}{\rho_{2} V_{\text {primary }}} \\
H_{L}=\frac{A_{L}}{\pi D_{L}} \\
\mathrm{PF}=1-\exp \left(-20 /\left[\left(L_{L} / H_{L}\right)\left(\Delta P_{L} / q_{\mathrm{ref}}\right)\right]\right)
\end{gathered}
$$

In the third step of the OD model, the primary, secondary, and dilution zone hole rows size and position are computed. For an annular combustion chamber, the number of holes in the liner for the primary and the secondary zone is recommended to be four times the number of fuel injectors. The holes are split in two opposite groups, relative to the internal and external walls of the liner. For the dilution zone, the number of holes $\left(n_{\text {dilution }}\right)$ is determined using the following equations (Eqs. (8) and (9)), where $C_{\text {dilution }}$ is 1.25 for inline dilution injection and 5 for staggered injection [14]. The parameter $J$ is computed using Eq. (8), where the jet subscript represents the properties of the gas passing through the liner holes and the index $g$ is for the properties inside the liner

$$
\begin{gathered}
J=\frac{\rho_{\text {jet }} V_{\text {jet }}^{2}}{\rho_{g} V_{g}^{2}} \\
n_{\text {dilution }}=\frac{\pi \sqrt{2 J}}{C_{\text {dilution }}}
\end{gathered}
$$

The sum of the total area of all holes is first calculated using mass conservation with a Mach number of 0.3 for the jet speed. The initial diameter of each hole is then computed knowing the number of holes for each combustor zone. Finally, the diameter of each hole is corrected using Eq. (10), where $C_{d}$ is a discharge factor of 0.55 [14], $d$ is the hole diameter, and $d_{\text {jet }}$ is the jet diameter through the hole

$$
C_{d}=\left(\frac{d_{\mathrm{jet}}}{d}\right)^{2}
$$

The holes in the first zone are placed axially near the injectors to promote vortices that improve the mixing of hot gas with entering fuel. The axial position of the holes for the second zone is equivalent to the height of the liner from the injectors. The axial position of the dilution holes is one and half times the height of the liner from the outlet of the combustion chamber.

The last step of the OD model is to determine the height of the air passages around the liner. In the passages, a flow velocity at a constant Mach number of 0.1 is to be set. To determine the height, conservation of mass is used, neglecting wall friction. The height is adjusted after each set of holes in the liner, according to the decrease in the air mass flow in the passageways.

6.2 Numerical Model. A numerical model is used to evaluate the combustor performance at the operating conditions. The process of optimizing the geometry of the combustion chamber is

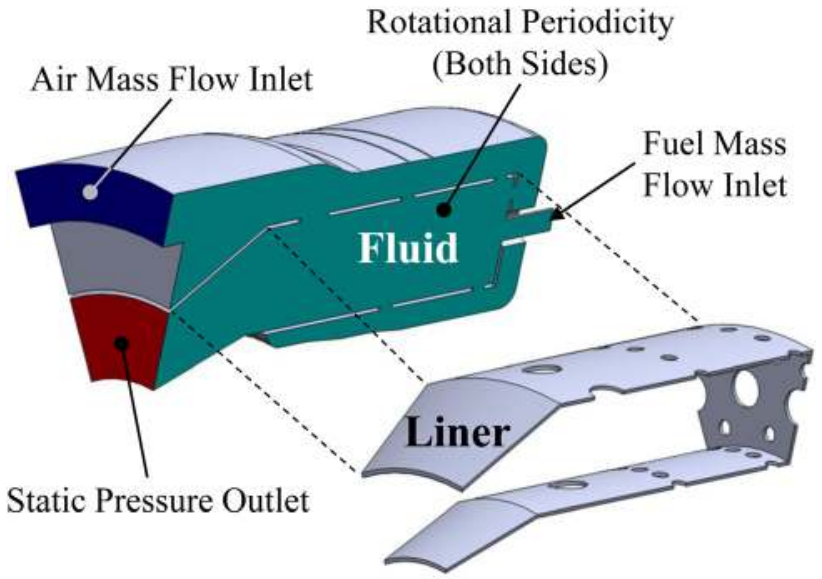

Fig. 10 Computational domain with the boundary conditions

made based on the design criteria outlined in Table 1. During optimization, the axial position, the diameter, and the number of the holes in the liner are adjusted until all the criteria are met. The dimensions of the passages around the liner are also adjusted to produce the most uniform flow speed.

Numerical simulations are run with ANSYS FLUENT ${ }^{\mathrm{TM}}$. Combustion is modeled by the transport equation of the mixture fraction using the nonpremixed combustion solver. This approach simplifies the calculation by preprocessing the thermochemistry for different mixture fractions for look-up by the combustion solver. A standard $\kappa-\varepsilon$ model is used to model turbulence for its good compromise between computing economy and accuracy [20]. The steady-state numerical model is solved using a coupled pressurebased solver with a second-order upwind discretization scheme for all field variables.

A tetrahedral mesh is used with a maximum cell dimension of $0.5 \mathrm{~mm}$. A mesh refinement is done near the liner holes to maintain sufficient accuracy. To allow for a better assessment of the interaction of the fluid with the wall, a gradual inflation of mesh size is added. A 36 deg axisymmetric sector is used as a computational domain (as shown in Fig. 10).

A periodic boundary condition is used at the two circumferential ends of the computational domain. Mass flow inlets are used for both air inlet and fuel inlet. A static pressure is set for the outlet. The outlet pressure is adjusted until all operating conditions at the inlet are met. Walls are considered adiabatic to simplify the simulation.

6.3 Prototype. Numerical evaluation of the OD model was sufficient for a first sizing, but multiple iterations on the combustor geometry were needed before it met all the design criteria. Table 3 shows the performance evaluation from the OD model and the final optimized model. Figure 11 shows the streamline and the temperature contour plot for the optimized model. Figure 12 shows the main dimensions of the final combustion chamber geometry for the $5 \mathrm{~kW}$ SRGT prototype design.

Table 3 Comparison between the combustor OD model and the optimize model

\begin{tabular}{lccc}
\hline Requirements & Objective & 0D model & Final model \\
\hline Pattern factor & $0.2-0.5$ & 0.66 & 0.33 \\
Total pressure loss $(\%)$ & $4-8$ & 9.4 & 7.1 \\
Average outlet temperature (K) & 1000 & 1322 & 1052 \\
Outlet Mach number & 0.25 & 0.28 & 0.25 \\
\hline
\end{tabular}


a)

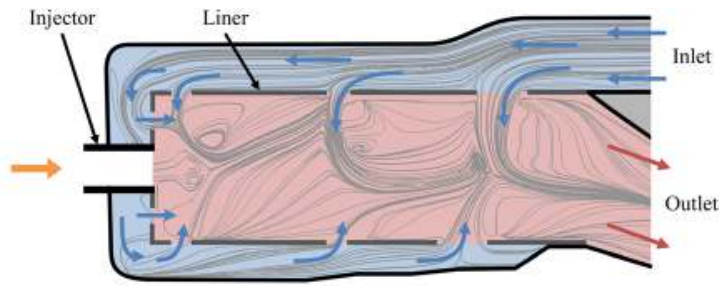

b)

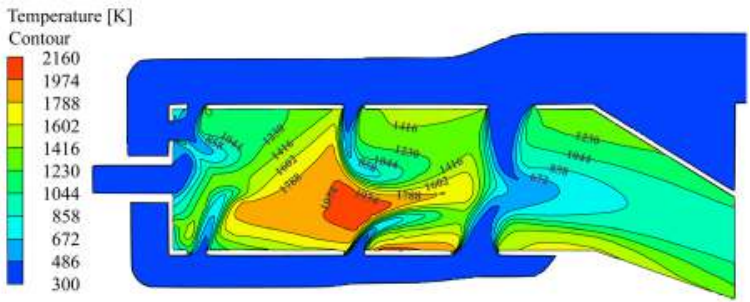

Fig. 11 Combustor CFD results of the optimized model: (a) streamline plot and $(b)$ temperature contour plot

\section{Structural Design}

The rotating assembly of the SRGT is comprised of four components: a titanium turbine and compressor, an aluminum ring, and an APC2/AS4 carbon fiber rim-rotor. The composite ring is manufactured using an automated fiber placement process with in situ curing. All the fibers are oriented in the hoop direction in order to provide maximum circumferential stiffness. The titanium and aluminum parts are machined using a conventional computerized numerical control milling machine. These concentric parts are then sequentially assembled into a single rotor using a shrink fitting process as shown in Fig. 13.

The analysis of stresses and strains in the engine is based on previous work by Rancourt [4] on the rim-rotor rotary ramjet engine (R4E), a small gas turbine configuration that also uses a rim-rotor. The assumption of $1 \mathrm{D}$ plane stress is made, and the carbon fiber ring is considered to have equal tensile modulus in both radial and tangential directions. For the current geometry and laminate, the latter assumption has shown to predict stresses within $15 \%$ of the values obtained using finite element simulations [21]. The radial displacements across the rotor are obtained by solving for radial equilibrium of forces in axisymmetric bodies subject to centrifugal forces

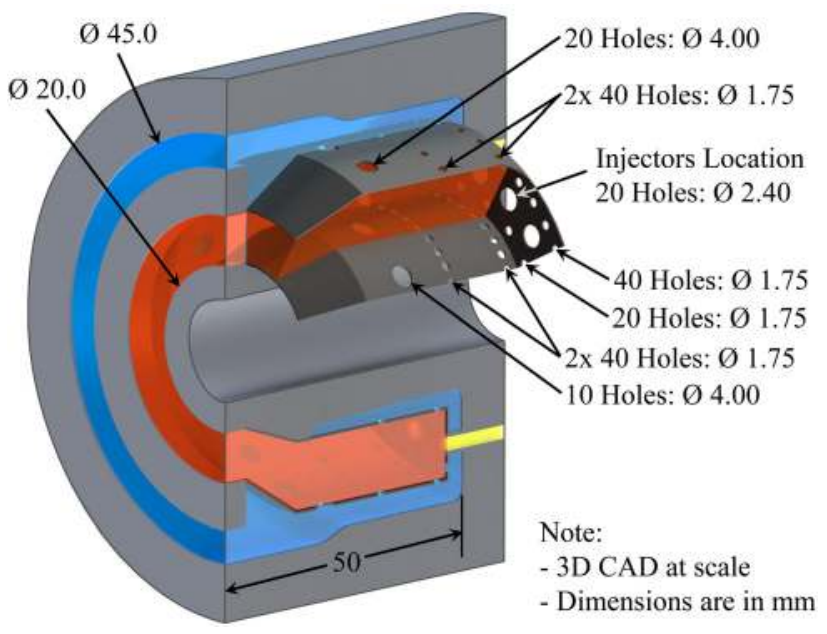

Fig. 12 Combustion chamber geometry

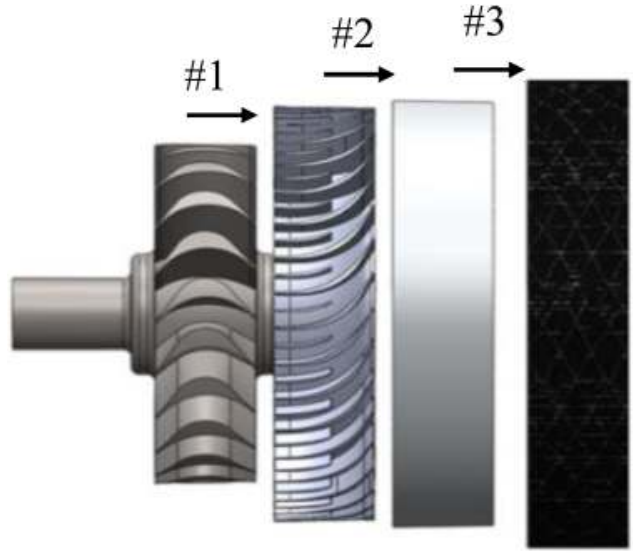

Fig. 13 SRGT interference fit assembly

$$
\frac{\mathrm{d} \sigma_{r}}{\mathrm{~d} r}+\frac{\sigma_{r}-\sigma_{\theta}}{r}+\rho r \omega^{2}=0
$$

As presented in several textbooks [22,23], a solution to this differential equation can be obtained by applying continuity of radial stresses and displacements along the radius of the rotor. From stress-strain relationships, expressions for radial and hoop stresses as a function of radius can be obtained. It is important to mention that, in the current study, the turbine and compressor blades are assumed to carry only radial stresses, as their discrete nature does not allow carrying tangential stresses (bar model). Thermal effects are taken into account by considering the radial strains of the components due to temperature $\left(\varepsilon_{\Delta T}=\alpha \Delta T\right)$. The mechanical properties of the selected titanium and aluminum alloys are also allowed to vary with temperature to account for the alteration in stiffness under high thermal loads [24]. Meanwhile, the properties of the carbon fiber laminate are assumed constant with temperature and its thermal expansion coefficient is assumed to be zero: a reasonable assumption providing the actual longitudinal coefficient of thermal expansion for APC2/AS4 is equal to $-0.2 \times 10^{-6} \mathrm{~m} / \mathrm{mK}[25]$.

The transient temperature analysis of each component is done using a simplified thermal model representing a $30 \mathrm{~s}$ combustion test at $125,000 \mathrm{rpm}$. Analysis showed that $30 \mathrm{~s}$ represent the steady-state conditions of the rotor. Initially, the engine components are assumed to be at a room temperature of $295 \mathrm{~K}$. The compressor blades are then subjected to an airflow at a temperature of $360 \mathrm{~K}$ and a convection coefficient of $h_{\text {conv,comp }}=700 \mathrm{~W} / \mathrm{m}^{2} \mathrm{~K}$ [26]. The turbine blades are exposed to the hot gases from the combustion chamber characterized by a temperature of $1000 \mathrm{~K}$ and a convection coefficient of $h_{\text {conv, turb }}=1000 \mathrm{~W} / \mathrm{m}^{2} \mathrm{~K}$. The computed average temperatures of the SRGT components after $30 \mathrm{~s}$ are shown in Table 4 . It can be observed that the heat transfer from the hot gases flowing in the turbine is heating the compressor rim and blades which are directly adjacent to the heat source. Through heat transfer effects, the protective aluminum ring and carbon fiber rim-rotor also experience a slight temperature rise over the timeframe studied.

Table 4 Mean temperature of each component after a combustion of $30 \mathrm{~s}$

\begin{tabular}{lc}
\hline Component & Temperature (K) \\
\hline Turbine hub & 755 \\
Turbine blade & 882 \\
Compressor rim & 607 \\
Compressor blade & 504 \\
Aluminum ring & 397 \\
Carbon fiber rim-rotor & 390 \\
\hline
\end{tabular}




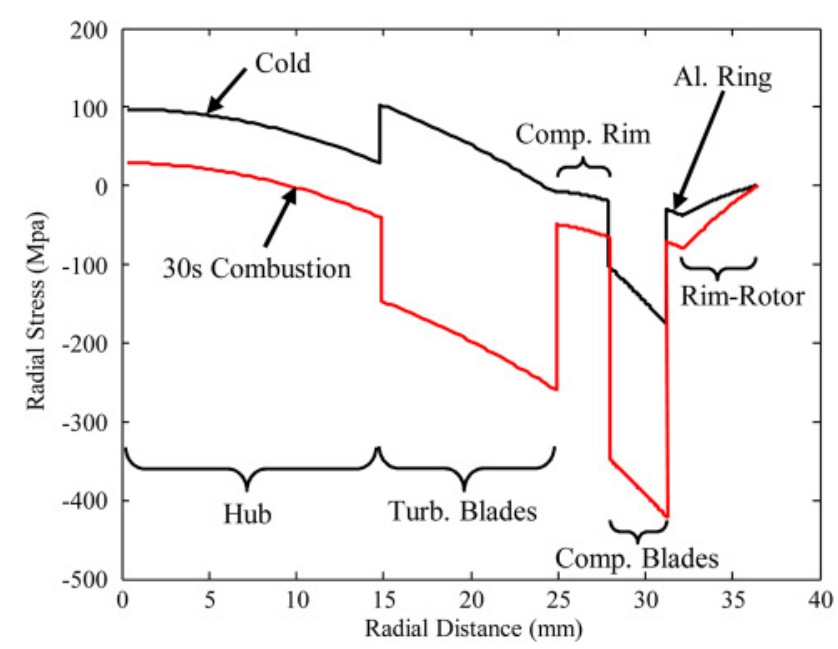

Fig. 14 Radial stresses at 125,000 rpm

As this engine is a part of an experimental setup, one of the critical design requirements is that the prototype must be able to operate anywhere between zero and $125,000 \mathrm{rpm}$ for both cold tests (no combustion) and hot tests (with combustion). In order to ensure contact between of the components of the rotor, the radial stresses at all the interfaces in Fig. 13 have to remain in compression, while remaining within the materials limit. The level of radial stress in the assembly is controlled by varying the amount of interference between the components prior to shrink fit. Figure 14 depicts the radial stresses in the engine for both the cold condition and after a $30 \mathrm{~s}$ combustion. For the cold condition, it is interesting to note that the inner part of the hub and turbine blades are in tension, with the radial stress shifting to compression at the interface between the turbine blades and compressor rim, with a slightly negative value of $-9.5 \mathrm{MPa}$. Heating of the components induces compressive forces in the assembly, resulting in a maximum radial stress at the compressor blades of $-420 \mathrm{MPa}$ (corresponding to a safety factor of 2.1). Therefore, the radial stress between the turbine blades and compressor for the cold case is the limiting factor for the maximum angular velocity of this prototype as the addition of heat only ensures compressive forces at all interfaces.

Figure 15 depicts the hoop stresses in the engine for both cold and hot operating conditions. It can be noted that these stresses are equal to zero in the blades as they carry only radial forces. Again, the heat generated after $30 \mathrm{~s}$ of combustion induces

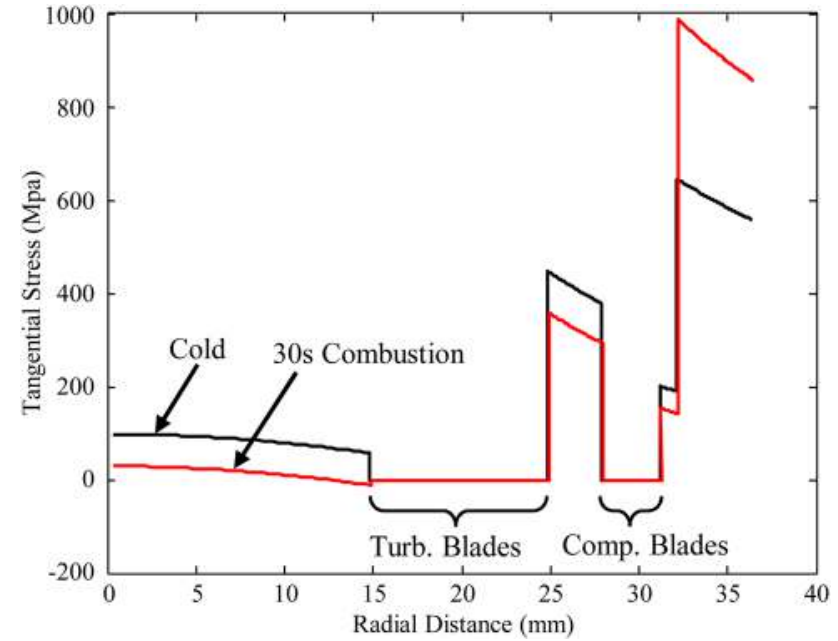

Fig. 15 Tangential stresses at $\mathbf{1 2 5 , 0 0 0 ~ r p m ~}$

compressive stresses in the turbine hub, compressor rim, and aluminum ring. Meanwhile, the carbon fiber rim-rotor is subject to tangential stresses as it must carry the radial compressive load generated by the pressure from the interference fits, thermal expansion, and centrifugal force. The maximum hoop stress in the rim-rotor is equal to $986 \mathrm{MPa}$, which leads to a safety factor of 2.1 with respect to the specifications provided by the manufacturer [27], assuming a maximum stress criterion in the hoop direction.

\section{Experimental Results}

8.1 Experimental Setup. The layout of the experimental setup is shown in Fig. 16, where the air inlet and the exhaust are both radial with a common wall. This configuration is a compromise for rotor dynamic and system integration. A volute and a heat shield are added at the inlet to prevent inlet air warm up and exhaust gas recirculation. The tested SRGT prototype is mounted on a Honeywell Garrett ${ }^{\circledR}$ GTX28 automotive turbocharger, replacing the compressor wheel, with the turbocharger capable to rotate up to $190,000 \mathrm{rpm}$ by blowing compressed air in the turbocharger turbine. The rotating assembly is dynamically balanced under GTX28 requirements $(0.5 \mathrm{~g} \mathrm{~mm})$ in two planes.

The rotational velocity of the prototype is monitored by an infrared sensor (Monarch Instrument, Amherst, NH, IRS) and mass air flow is measured at the inlet by a venturi tube. Hydrogen

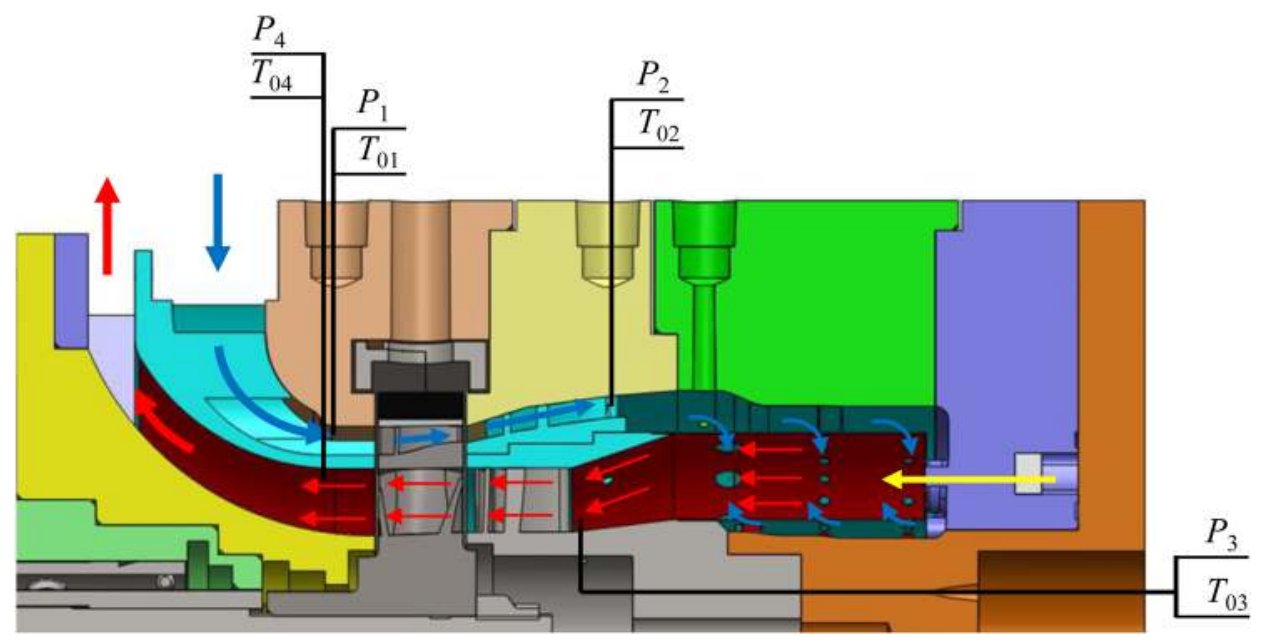

Fig. 16 Experimental setup detailed cross section 
is injected at the back of the combustion chamber through 19 injector holes of $2.4 \mathrm{~mm}$ and is regulated by a mass flow controller (Alicat, Tucson, AZ, MCR-1500). An MSD Blaster ${ }^{\circledR}$ ignition inductive system is used to provide high voltage to the spark igniter in the combustion chamber. Total temperatures are measured at stations (i 1, 2, 3, 4, and e) of the system with standard K-type thermocouples. Static pressures are also measured with differential pressure transducers (SSI Technologies, Janesville, WI, P51 model) at the same stations of the system, using $1.5 \mathrm{~mm}(1 / 16 \mathrm{in}$.) O.D. tubes flush-mounted to the wall. The external temperature of the carbon fiber rim-rotor is measured with an infrared sensor (Omega, Stamford, CT, OS36).

8.2 Steady-State Test. Tests were performed to validate the operation of the titanium SRGT prototype in steady state with hydrogen combustion. The objectives of this test were to validate the structural integrity of the prototype in steady state, to characterize the combustion chamber, and try to produce indicated power. After ignition, combustion is maintained for $30 \mathrm{~s}$ to allow the prototype to accelerate to a constant speed and achieve an aerodynamic and thermal steady state.

During the test, the prototype was first accelerated using an external starter up to a rotational speed of $102,000 \mathrm{rpm}$. The combustion chamber was then ignited and the prototype accelerated to a speed of 117,000 rpm (as shown in Fig. 17). Figure 18 shows the curves of temperature and equivalence ratio as a function of time during the test. The temperature curve at the turbine inlet is hatched after $75 \mathrm{~s}$ due to thermocouple failure. Since the temperature of the outlet of the turbine remains constant after the 75-s mark, it is possible to believe that the turbine inlet temperature has kept the same trend. Oscillations after ignition come from the flow rate adjustment of fuel to maintain an exit temperature of $1000 \mathrm{~K}$; upon ignition, the hot gases in the combustion chamber created an increase in back pressure, causing a drop in air mass flow in the compressor, requiring the fuel flow to be corrected. A better fuel controller adjustment would be needed to shorten the oscillation time. The average exit temperature observed during steady state is $975 \mathrm{~K}$.

During the prototype acceleration without combustion, for speeds under $40,000 \mathrm{rpm}$, experimental mass flow rates match within $8 \%$ of the values obtained from the model. At $50,000 \mathrm{rpm}$, the experimental mass flow rate is $15 \%$ under the model. At speeds over $90,000 \mathrm{rpm}$, the mass flow rate error is greater than $40 \%$. After ignition, during steady-state combustion, the air mass flow never exceeds $60 \mathrm{~g} / \mathrm{s}$, instead of the $130 \mathrm{~g} / \mathrm{s}$ anticipated at the design point.

The significant lower mass flow suggests that the compressor never started in supersonic mode, limiting the compressor to offdesign operation. The maximum pressure ratio obtained from the

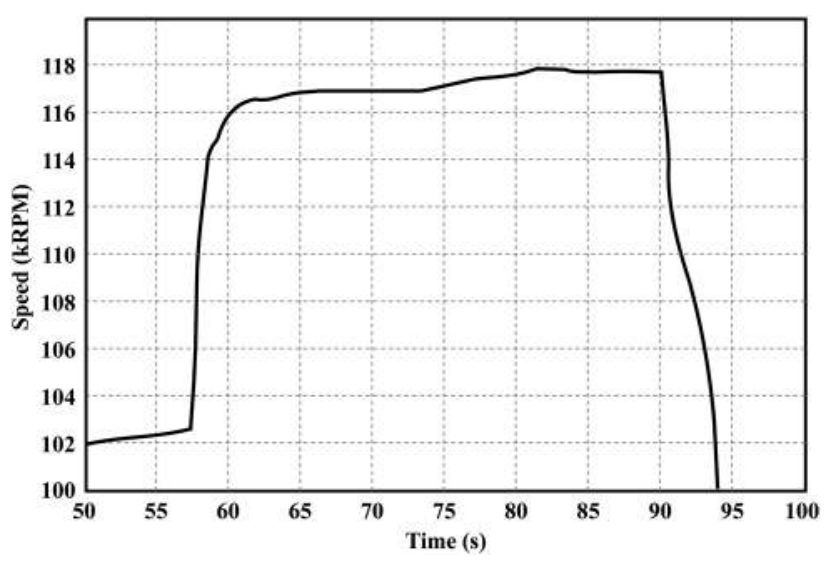

Fig. 17 Acceleration of the prototype after ignition

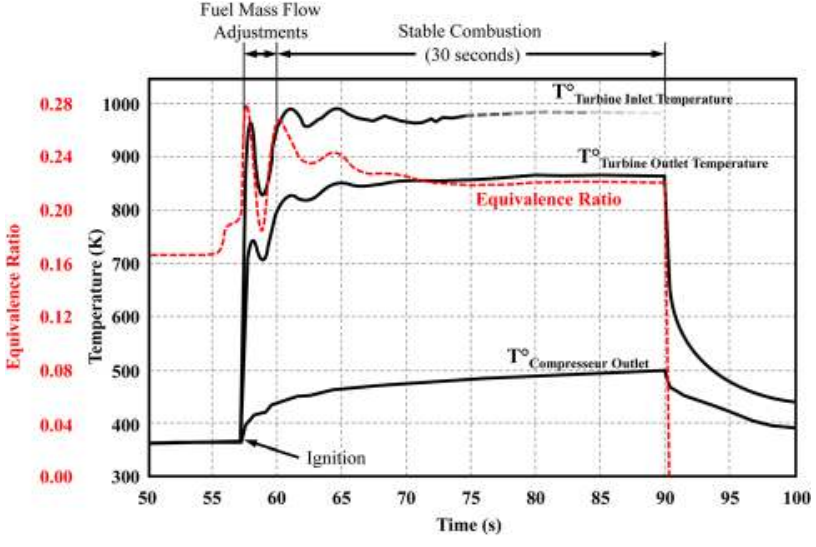

Fig. 18 Temperatures and equivalence ratio during combustion

prototype compressor was 1.38 with an isentropic efficiency of $45 \%$. The lower experimental mass flow is probably due to boundary layer separation on suction surface near the leading edge of the rotor and stator compressor blades. The flow separation reduces the effective area for the passage of air, which causes an earlier choking than anticipated in the models. In turn, the lack of air mass flow causes a mismatch between the blade geometries and the operating velocity triangle, probably resulting in an unstable shock wave pattern. These effects explain the low isentropic compression efficiency.

The nonstarted supersonic condition of the compressor also has repercussion on the turbine since limitations on air mass flow and pressure ratio will also force the turbine to operate unstarted and off-design. This undesirable situation limits the interpretation of the results to compare the performance of the turbine stage with its analytical model.

Combustion efficiency is calculated by comparing the turbine inlet temperature with the value obtained from an equilibrium combustion solver at constant pressure and enthalpy. From this, combustion efficiency is found to be at least $85 \%$, considering that the heat transfer to the walls and the bypassing gases from 3.5 to 1.5 in Fig. 2 are neglected. Further design optimization is needed to minimize bypassing flow, but this first test demonstrated quick ignition and stabilization of a hydrogen flame in the combustor. The combustor total pressure losses measured in the test were $4.3 \%$, compared to the $4.7 \%$ estimated by the numerical simulation at the same operating conditions. This shows good agreement at this stage of SRGT development between the numerical model and the experimental results.

The test also allowed the structural models used to be validated during the design process. It was anticipated that the titanium compressor and turbine imbedded in the carbon composite rimrotor should resist to rotational speeds of $125,000 \mathrm{rpm}$ for $30 \mathrm{~s}$ with a turbine inlet temperature of $1000 \mathrm{~K}$. After the test, besides discoloration of the turbine, the prototype did not show any sign of structural failure or heat damage.

The ignition tests have shown that for a constant starter mechanical power, the prototype accelerates and the compressor continuously consumes more power. The gain of instantaneous power comes from a turbine gain efficiency of approximately $1000-2000 \mathrm{~W}$ for the first half second after ignition. The experimental instantaneous power gain is evaluated using the prototype acceleration and its measured inertia of $10.13 \times 10^{-5} \mathrm{~kg} \mathrm{~m}^{2}$. However, this experimentation could not demonstrate that the turbine provided net power.

\section{Summary and Conclusions}

A new architecture of micro gas turbine using a single rotor supersonic concentric counterflow, called SRGT, is designed and tested to validate its potential to increase engine power density 
while significantly reducing the manufacturing costs. The SRGT uses a single rotating assembly incorporating a central hub, a supersonic turbine rotor, a supersonic compressor rotor, and a rim-rotor. A supersonic impulse compressor increases the air pressure in a very short distance using normal shock waves. Subsonic combustion using hydrogen takes place in an annular reverse-flow combustion chamber, with the inlet and the exhaust on the same side of the rotating disk. Combustion products are finally expanded in the supersonic turbine and then converted into mechanical power.

A first design iteration loop is done by designing and testing an SRGT prototype. The aerodynamic layout, the combustion chamber, and the structure of the prototype are all studied during this first iteration. For the aerodynamic model, a quasi-1D model is developed to size and estimate the performances of the different components. The analytical model includes component geometry, friction losses, heat transfer, and windage losses. The quasi-1D model predicts an air mass flow of $130 \mathrm{~g} / \mathrm{s}$ at $125,000 \mathrm{rpm}$ with a pressure ratio of 2.75 . With a turbine inlet temperature of $1000 \mathrm{~K}$, the prototype is projected to produce $5 \mathrm{~kW}$ of power.

The combustion chamber is first sized with empirical equations from a OD model using the Mellor [19] design process. The optimization process is then performed using a full 3D CFD numerical analysis until all the design requirements are met. The proposed combustion chamber design is an annular reverse-flow configuration, using hydrogen as fuel. The average outlet temperature is predicted to be $1052 \mathrm{~K}$ with a total pressure loss in the combustor of $7.1 \%$.

The rotating assembly of the SRGT is comprised of four components: a titanium turbine and compressor, an aluminum ring, and an APC2/AS4 carbon fiber rim-rotor. To estimate the stress, strain, and displacement, a simple analytic model is developed. The stresses and strains are solved using the assumption of 1D plane stress in the components. The radial displacements across the rotor are obtained by solving for radial equilibrium of forces in axisymmetric bodies subject to centrifugal forces. For the current geometry and laminate, the latter assumption has shown to predict stresses within $15 \%$ of the values obtained using finite element simulations. To estimate component temperatures, a simplified numerical model is used. Results from the different models predict the structural integrity of the prototype at $1000 \mathrm{~K}$ during $30 \mathrm{~s}$ at $125,000 \mathrm{rpm}$.

A prototype is fabricated to validate the results from the aerodynamic, structural, and combustion analysis. Results from a steady-state test show that the proposed concept can sustain the mechanical stresses caused by high rotational speed with a turbine inlet temperature of $1000 \mathrm{~K}$ for $30 \mathrm{~s}$. Ignition and stable combustion are demonstrated with hydrogen fuel. A combustion efficiency of more than $85 \%$ is reached. An acceleration from 102,000 to $117,000 \mathrm{rpm}$ was demonstrated. Although it is not possible to prove the production of indicated power during the acceleration, a power gain of $1500 \mathrm{~W}$ was measured. The early chocking and low isentropic efficiency of the compressor limited the mass flow and pressure ratio necessary to reach the net power expected. For the SRGT to produce net power, a refined study using detailed CFD for both compressor and turbine would be necessary to increase the accuracy of the performance predictions and adjust the analytical model. Also, seals would be needed to prevent hot gas recirculation.

Despite the fact that no indicated power was produced during the steady-state test, power gain and structural integrity of the prototype after 30 s prove that the SRGT architecture based on a carbon fiber/ polymer rim-rotor to be structurally viable. These results are encouraging in the pursuit of the development of SRGT or design derivatives that have the opportunity to increase the power density of gas turbines while maintaining low manufacturing costs.

\section{Acknowledgment}

The authors would like to mention the important contribution for the rim-rotor design and manufacturing of Ali Yousefpour and
Jihua Chen from the National Research Council Canada. The authors would also like to thank Pierre-Yves Givreau, Benoit Dupont, and Nicolas Courtois for their countless hours on the experimental setup. This work was made possible thanks to the financial support of the Natural Sciences and Engineering Research Council of Canada (NSERC).

\section{Nomenclature}

$A=$ cross section area

$C=$ coefficient

$C_{d}=$ discharge factor

$C_{f}=$ Fanning friction factor

$c_{p}=$ specific heat at constant pressure

$d=$ hole diameter

$D=$ diameter

$h=$ enthalpy

$H=$ height

$h_{\text {conv }}=$ convection coefficient

$J=$ momentum-flux ratio

$L=$ rim-rotor length

$\dot{m}=$ mass flow rate

$M=$ Mach number

$n=$ number of holes

$N=$ angular speed

$P=$ pressure

$\mathrm{PF}=$ pattern factor

$\mathrm{PR}=$ pressure ratio

$q=$ dynamic pressure

$Q=$ heat

$r=$ radius

$R=$ individual ideal gas constant

$\mathrm{Re}_{r}=$ Reynolds number based on radius

$T=$ temperature

$V=$ flow velocity

$\dot{W}=$ power

$x=$ component length

\section{Greek Symbols}

$$
\begin{aligned}
\alpha & =\text { thermal expansion coefficient } \\
\gamma & =\text { ratio of specific heat } \\
\varepsilon & =\text { strain } \\
\nu & =\text { kinematic viscosity } \\
\rho & =\text { density } \\
\sigma & =\text { stress } \\
\omega & =\text { angular velocity } \\
\varnothing & =\text { diameter }
\end{aligned}
$$

\section{Subscripts}

comp $=$ relative to the compressor

dilution $=$ about the combustor dilution zone

$e=$ exhaust station

$g=$ relative to gas properties inside the liner

$h=$ hydraulic

$i=$ intake station

jet $=$ relative to gas properties passing through the liner holes

$L=$ about the combustor liner

$P=$ passages around the liner

primary $=$ about the combustor primary zone

$r=$ in radial coordinate

ref $=$ reference

$\mathrm{rel}=$ station in rotating frame

$\mathrm{RR}=$ relative to the rim-rotor

turb $=$ relative to the turbine

$0=$ stagnation properties

$1=$ compressor inlet station

$2=$ compressor outlet station (combustion chamber inlet) 


$$
\begin{aligned}
& 3=\text { turbine inlet station (combustion chamber outlet } \\
& \quad \text { station) } \\
& 4=\text { turbine outlet station } \\
& \theta=\text { in tangential coordinate }
\end{aligned}
$$

\section{References}

[1] Walsh, P. P., and Fetcher, P., 2004, Gas Turbine Performance, Wiley, Oxford, UK.

[2] Brouillette, M., and Plante, J.-S., 2008, "Rotary Ramjet Engine," U.S. Patent No. $7,337,606$

[3] Cool Cain, E. F., 1981, "Ceramic Gas Turbine Rotor," UK Patent Application No. 2,069,06.

[4] Rancourt, D., Picard, M., Denninger, M., Chen, J., Yousefpour, A., and Plante, J.-S., 2012, "A High Power Density Rim-Rotor-Rotary Ramjet Engine. Part 1: Structural Design and Experimental Validation," AIAA J. Propul. Power, 28(6), pp. 1293-1303.

[5] Picard, M., Rancourt, D., Plante, J.-S., and Brouillette, M., 2012, "A High Power Density Rim-Rotor-Rotary Ramjet Engine. Part 2: OneDimensional Aerothermodynamic Design," AIAA J. Propul. Power, 28(6), pp. 1304-1314.

[6] Gros, J.-M. G., and Gros, M. J.-C., 1988, "Compresseur Roue de Turbine Monobloc, Redresseur Distributeur Monobloc, Entrée d'air Tuyère D'échappement Monobloc," FR Patent Application No. 2,613,772-A1.

[7] Daimler-Benz, A. G., 1961 "Improvements Relating to Gas Turbine Power Plants," GB Patent Application No. 884,646.

[8] Hayes, J. M., 2008, "Counter Flow Single Rotor Turbojet and Method," U.S. Patent No. 5,224,339.

[9] Plante, J.-S., Rancourt, D., and Picard, M., 2011, "Supersonic Rim-Rotor Gas Turbine," U.S. Patent Application No. US61/538'201.

[10] Saravanamuttoo, H. I. H., Rogers, G. F. C., Cohen, H., and Straznicky, P. V., 2008, Gas Turbine Theory, Pearson Education Limited, Harlow, UK.

[11] Shapiro, A. H., 1953, The Dynamics and Thermodynamics of Compressible Fluid Flow, Vol. 1, Ronald Press Company, New York.

[12] ANSYS, 2009, ANSYS CFX Reference Guide, Release 12.1, Ansys Inc., Canonsburg, PA.

[13] Ferguson, C. R., and Kirkpatrick, A. T., 2000, Internal Combustion Engines: Applied Thermoscience, Wiley, New York.
[14] Lefebvre, A. H., and Ballal, D. R., 2010, Gas Turbine Combustion: Alternative Fuels and Emissions, CRC Press, Boca Raton, FL.

[15] Saint-Raymond, M., Kasarda, M. E. F., and Allaire, P. E., 2008, "Windage Power Loss Modeling of a Smooth Rotor Supported by Homopolar Active Magnetic Bearings,” ASME J. Tribol., 130(2), p. 021101.

[16] Etemad, M. R., Pullen, K., Besant, C. B., and Baines, N., 1992, "Evaluation of Windage Losses for High-Speed Disc Machinery," SAGE J. Power Energy, 206(3), pp. 149-157.

[17] Gallus, H. E., Bohn, D., and Broichhausen, K. D., 1979, "Unsteady Upstream Effects in Axial-Flow Supersonic Compressor Stages," ASME Paper No. 79GT-55.

[18] Ijichi, N., Ono, H., Nakano, K., Takeo, K., Onosato, H., and Tsukamoto, M. 1998, "Development of a High Expansion Ratio, Single-Stage Axial Turbine for Marine Turbocharger," 6th International Conference on Turbocharging and Air Management Systems, London, Nov. 3-5, IMechE Paper No. C554/009/98, pp. 303-314.

[19] Mellor, A. M., 1990, Design of Modern Turbine Combustors, Academic Press, New York.

[20] Fortier-Topping, H., and Vézina, G., 2013, "Design and Sensitivity Study of a Combustion Chamber of a Supersonic Rim-Rotor Gas Turbine (SRGT) Engine," 21st Annual Conference of the CFD Society of Canada, Sherbrooke, Canada, May 6-9.

[21] Etemad, M. R., Pask, E., and Besant, C. B., 1992, "Hoop-Strength Characterization of High-Strength Carbon Fibre Composites," Composites, 23(4), pp. 253-259.

[22] Bazergui, A., Bui-Quoc, T., Biron, A., McIntyre, G., and Laberge, C., 2002, Resistance des Materiaux, Presses Internationales Polytechnique, Montreal, QC, Canada.

[23] Young, W. C., and Budynas, R. G., 2002, Roark's Formulas for Stress and Strain, McGraw-Hill, New York.

[24] Kaufman, J., 1999, Properties of Aluminum Alloys: Tensile, Creep and Fatigue Data at High and Low Temperature, ASM International, Washington, DC.

[25] Daniel, I. M., and Ishai, O., 2005, Engineering Mechanics of Composite Materials, Oxford University Press, Oxford, UK.

[26] Rancourt, D., 2011, "Analyse Structurelle et Validation Experimentalle d'un Rim-Rotor Rotary Ramjet Engine (R4E)," Master's thesis, Universite de Sherbrooke, Sherbrooke, QC, Canada.

[27] Cytec Engineered Materials, 2012, APC-2 PEEK Thermoplastic Polymer, Technical Data Sheet, Tempe, AZ. 